\title{
Aspects of frailty syndrome, nutritional status and comorbidities in the elderly
}

\author{
${ }^{\star}$ Felicia Lupascu-Volentir, Gabriela Soric, Ana Popescu, Anatolie Negara
}

Scientific Laboratory of Gerontology, Department of Geriatrics and Occupational Medicine

Nicolae Testemitanu State University of Medicine and Pharmacy, Chisinau, the Republic of Moldova

Authors' ORCID iDs, academic degrees and contributions are available at the end of the article

Corresponding author - Felicia Lupascu-Volentir, e-mail: felicia.lupascu@usmf.md

Manuscript received April 26, 2021; revised manuscript July 05, 2021; published online December 17, 2021

\begin{abstract}
Background: Frailty syndrome is one of the most important multifactorial medical syndromes, which is characterized by a decrease in functionality of many systems and organs.

Material and methods: In order to establish the nutritional determinants that contribute to the onset of frailty syndrome, a study was performed on a group of 50 patients, aged $\geq 65$ years with chronic pathologies and geriatric syndromes. All participants were examined according to clinical features (history, clinical examination), Mini Nutritional Assessment and of the Complex Geriatric Assessment, which included: the data of the frailty tools, age category, Vulnerable Elders Survey, Charlson Comorbidity Index, autonomy - Activity Daily Living, Instrumental Activity Daily Living, Tinetti scale, psychoaffective status - by memory test Mini-Mental State Examination and the Geriatric Scale of Depression in the context of nutrition in the elderly. A clustered analysis ( $k$-means method) of nutritional status showed that the most relevant indicators that separated the clusters were: age category, gender, clinical scale of frailty, comorbidities and polymedication.

Results: Frailty through the multidimensional aspects that it meets has an increased prevalence among the elderly with an unfavorable prognosis. Following the proposed study, it was revealed that insufficient nutrition and comorbidities can lead to the weakening of the institutionalized age. The results obtained by evaluating the bio-psycho-social aspects characterize the profile of the institutionalized elderly and can be used as a basis for the development of effective strategies aimed at reducing physical, cognitive and social frailty.

Conclusions: The comparative evaluation between both groups of elderly people by gender, showed a normal nutritional status with a higher share in women in the group of 75-84 years, compared to older men, and malnutrition was practically manifested equally in both groups in the study (men/women) Key words: nutritional status, frailty, comorbidities, elderly.
\end{abstract}

\section{Cite this article}

Lupascu-Volentir F, Soric G, Popescu A, Negara A. Aspects of frailty syndrome, nutritional status and comorbidities in the elderly. Mold Med J. 2021;64(6):20-25. https://doi.org/10.52418/moldovan-med-j.64-6.21.04.

\section{Introduction}

The concept of frailty is increasingly attracting the interest of specialists, being widely used in scientific research and medical practice. According to consensus of international experts in 2013, frailty is characterized by a decrease of functionality in several systems and organs, accompanied by increased vulnerability to stressors, falls, frequent hospitalizations, long-term care and increased mortality [1-3]. A major problem is the fragile lonely and institutionalized elderly persons [4-6].

Frailty, comorbidity and disability are three interdependent clinical entities, which have only recently been shown to be distinct, and their multidimensional assessment should insist on a geriatric clinical decision. Recent research has shown that there is a constant category of frail people with no comorbidities or disabilities $[2,7]$. In the context of new changes resulting from the need to formulate certain approaches to solving the problems of the elderly, there is a need for new scientific research in the field of geriatrics, so one of the most relevant, but at the same time little understood, is the frailty syndrome one of the most important multifactorial medical symptoms.

Frailty often precedes disability, while disability and comorbidity can contribute to the development of frailty [8]. In addition, increased attention was paid to the subtypes of frailty: social, functional, nutritional and cognitive $[9,10]$. At the same time, the role of nutrition as a means of delaying frailty in the elderly is well established.

Insufficient dietary intake is often associated with multiple conditions, such as: increased risk of chronic diseases and osteoporotic fractures, impaired immune responses, frailty. Assessment of nutritional status and diagnosis of malnutrition requires a variety of nutritional screening tools and laboratory biochemical markers [10].

Currently, the literature does not fully elucidate the nutritional determinants that would contribute to the emergence of frailty syndrome and its impact on public health. Identifying and integrating these factors would help phy- 
sicians and geriatric care teams in developing prevention and treatment strategies for the vulnerable population. Numerous recent studies have highlighted data on the prevalence of frailty and various factors that most often influence its appearance and development. The presence of frailty is considered a predictor of negative prognosis and high rates of morbidity and mortality. Given the increasing incidence of different types of frailty among the elderly population in many countries and the unfavorable prognosis of frail patients, there is a need for a number of clinical trials to implement measures for primary and secondary prevention and effective methods of preventing and treating frailty and, in particular, nutritional frailty.

The purpose of the study was to assess aspects of frailty syndrome, nutritional status and comorbidities according to the gender of the elderly.

\section{Material and methods}

The epidemiological study was part of the Institutional Project 20.80009.8007.25 Frailty: diagnosis and prevention in relation to the medico-psycho-social problems of the vulnerable elderly, with a positive opinion of the Ethics Committee with No 51 of 16.06.2020, which included 50 elderly people between 65 and 93 years old, institutionalized at the Republican Asylum for the Disabled and Retired.

The inclusion criteria were: the elderly $\geq 65$ years with chronic somatic pathologies and geriatric syndromes, and the exclusion criteria: the elderly with various forms of dementia and oncology. The study was conducted in November-December 2020. Members were enrolled in research only after signing the informed consent to participate in the study.

All participants were examined according to clinical features (history, clinical examination) and the Complex Geriatric Assessment, which included: the data of the frailty phenotype and the frailty index - Fried's criteria, Gröningen Frailty Index (GFI) [11, 12], nutritional score - Mini Nutritional Assesment (MNA) [13], sarcopenia SARC-F (A Simple Questionnaire to Rapidly Diagnose Sarcopenia) [14], age category [15], VES-13 (Vulnerable Elders Survey) [16], SPPB (The Short Physical Performance Battery) [12], Charlson Comorbidity Index [12], physical status by assessment of autonomy - ADL (Activity Daily Living), IADL (Instrumental Activity Daily Living) [17] and gait /balanceTinetti scale [18], MMSE (Mini-Mental State Examination) [19], the geriatric scale of depression in the context of nutrition in the elderly [13].

The data obtained from the programed investigations were analyzed by methods of variational, correlational and cluster analysis in the STATISTICA 6.0 software package.

\section{Results and discussion}

The study was performed on a group of 50 people, aged between 65-93 years, the average being 78 years. Females (80.64\%) versus males (19.36\%) predominated.

A multidisciplinary approach of understanding the determinants of frailty is the key to success in geriatric populations. The phenomenon of clinical frailty includes 3 fundamental aspects of evaluation: standardized geriatrics, clinical examination and the social side. Currently, the literature emphasizes the bio-psycho-social model of frailty, which includes areas such as: cognitive and mood disorders, functional deficiencies, malnutrition or lack of social support [9].

The results of this study presented data of the social subtype of the elderly placed in the nursing home, where according to the jobs they performed - workers predominated (58\%), followed by intellectuals $(30 \%)$ and peasants $(12 \%)$, by the level of education, they were distributed as follows: secondary and higher $-68 \%$, primary school $-20 \%$ and without education $-12 \%$.

According to the international code of diseases [20], the morbidity structure was established in the Republican Asylum for the Disabled and Retired in the evaluated period, from the number of concomitant diseases of the elderly, cardiovascular pathology prevailed $-74 \%$ of cases, followed by vision disorders $-66 \%$ and hearing impairment $-66 \%$, neurological pathology $-64 \%$, osteoarticular $-42 \%$, digestive $-28 \%$, diabetic $-18 \%$ and pulmonary $-6 \%$.

After examining the nutritional indicator score (MNA): $38 \%$ had normal nutritional status, $40 \%$ - risk of malnutrition and $22 \%$ were malnourished.

In the specialized works of the last years, the researchers reported the complexity of the frailty syndrome in the elderly population, mentioning the importance of Complex Geriatric evaluation through certain grids, in terms of establishing subtypes of frailty: functional - ADL, IADL, GFI, SPPB, VES-13, SARC-F, gait and balance - Tinetti, cognitive - MMSE and bio-psycho-social (Charlson Comorbidity Index) $[12,21,22]$.

Vermeulen J. et al. [8] noted that frail people from a multidimensional perspective of impairment are susceptible to a higher risk of functional frailty determined by the ADL score, and researchers Batko-Szwaczka A. et al. [23], Bekić S. et al. [24], Montero-Odasso MM. et al. [25], highlighted the phenotype of frailty through the prism of physical and mental determinants in the risk of frailty.

Pearson's correlation analysis of geriatric scores established high positive correlations between the Charlson Comorbidity Index - Gröningen Frailty Index $\left(r=0.56^{*}\right)$, Activity Daily Living - Instrumental Activity Daily Living $\left(\mathrm{r}=0.61^{\star}\right)$, Activity Daily Living - gait and balance Tinetti $\left(\mathrm{r}=0.62^{\star}\right)$, Instrumental Activity Daily Living - gait and balance Tinetti $\left(r=0.68^{\star}\right)$, Gröningen Frailty Index - A Simple Questionnaire to Rapidly Diagnose Sarcopenia ( $\mathrm{r}=$ $\left.0.69^{\star}\right)$, The Short Physical Performance Battery - gait and balance Tinetti score $\left(r=0.62^{*}\right)$ and maximum correlation between Gröningen Frailty Index - Geriatric Depression Scale $\left(\mathrm{r}=0.78^{\star}\right)(\mathrm{p} \leq 0.05)$, results confirmed in other specialized works [8]. The high degree of correlation between the scores indicates that there is a pronounced positive dependence between the levels of their expression. In the case of $\mathrm{ADL}$ and IADL scores, this dependence is natural, be- 
cause both scores show the degree of functionality of the elderly, so the higher the value of the ADL score, the higher the value of the IADL. The Charlson Comorbidity Index correlation with Gröningen Frailty Index demonstrates that, the Charlson Comorbidity Index being a marker of chronic comorbidities, Gröningen Frailty Index is sensitive to the process of weakening the vulnerable elderly (fig. 1,2).

The analysis of the statistical results of a study in 2011 on a group of 81 patients showed that frailty correlates with age and moderate cognitive impairment, and another study conducted on a group of 185 participants showed that nutrition is negatively correlated with cognitive frailty $[26,27]$.

In our work, the correlational analysis of Mini Nutritional Assesment and Mini-Mental State Examination established high negative correlations between Mini Nutritional Assesment - Geriatric Depression Scale $\left(\mathrm{r}=-0.78^{\star}\right)$, Mini Nutritional Assesment - Gröningen Frailty Index $\left(r=-0.73^{\star}\right)$, Mini Nutritional Assesment Charlson Comorbidity Index $\left(r=-0.54^{\star}\right)$, Mini-Mental State Examination - Gröningen Frailty Index $\left(r=-0.56^{*}\right)$ $(\mathrm{p} \leq 0.05)$, which shows that at a high nutritional value, there is the risk of developing functional, cognitive, psychological frailty and chronic comorbidities (fig. 3, 4).

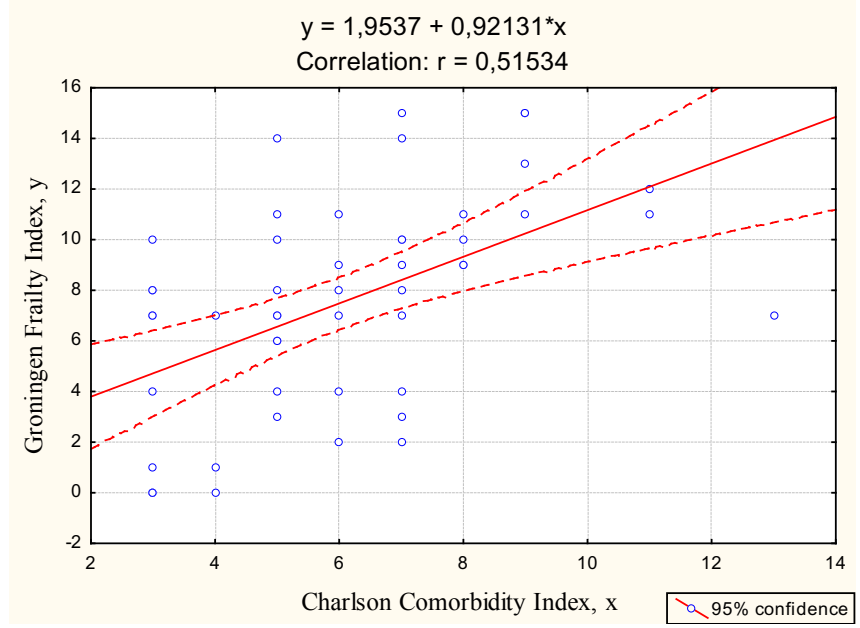

Fig. 1. Correlation and linear regression between the Charlson Comorbidity Index and the Gröningen Frailty Index

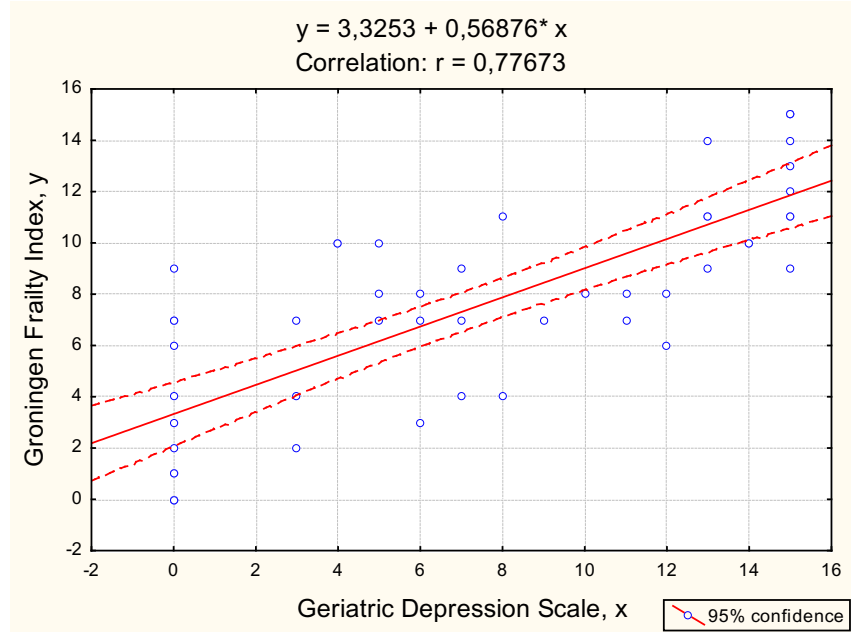

Fig. 2. Correlation and linear regression between Gröningen Frailty Index and Geriatric Depression Scale

Depression is the leading cause of mental suffering as we age and affects morbidity and geriatric patients. In the case of this study, e.g. Mini Nutritional Assesment Geriatric Depression Scale or Mini Nutritional Assesment - Gröningen Frailty Index at a high nutritional value, decreases the risk of developing depression and frailty of the vulnerable elderly.

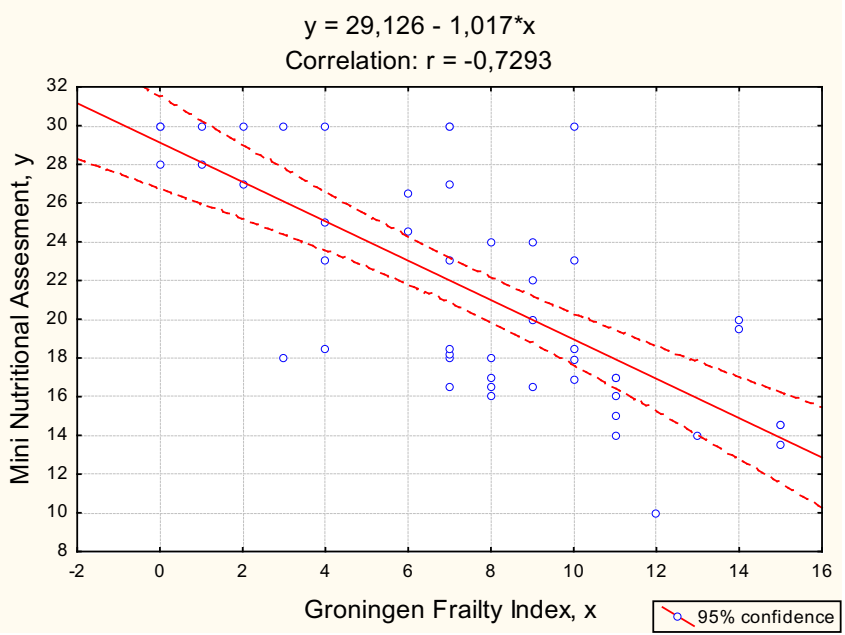

Fig. 3. Linear correlation and regression between Mini Nutritional Assesment and Gröningen Frailty Index

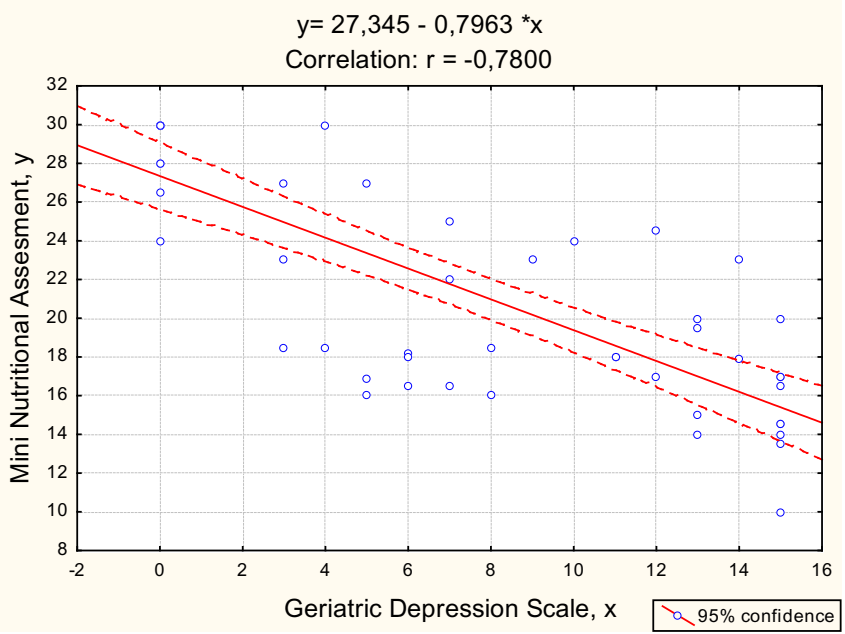

Fig. 4. Correlation and linear regression between index MNA and Geriatric Depression Scale

Based on the correlational analysis, the regression analysis was performed, which indicates not only the degree of dependence $(0.00 \ldots 1.0)$ and the orientation between factors (+/-), but also the mathematical equation of the obtained correlations, which has a predictive importance in medical practice. Taking into account the determining role of the frailty and nutritional risk of the vulnerable elderly, it was established as an independent factor in the regression analysis. Thus, for the correlations Gröningen Frailty Index - Geriatric depression scale $\left(r=0.78^{\star}\right)$, the Comorbidity 
Table 1. Clustered analysis of nutritional status (MNA) by age, gender, clinical scale of frailty, comorbidities and drugs

\begin{tabular}{|c|c|c|c|c|c|c|c|}
\hline \multicolumn{4}{|c|}{ Women, n=31 } & \multicolumn{4}{|c|}{ Men, $n=19$} \\
\hline Cluster & \multicolumn{3}{|c|}{ Frequent indices in clusters } & Cluster & \multicolumn{3}{|c|}{ Frequent indices in clusters } \\
\hline \multirow[t]{13}{*}{$1, n=14$} & \multirow{3}{*}{\multicolumn{2}{|c|}{$\begin{array}{c}\text { MNA } \geq 24 \\
\text { MNA }(17-23,5) \\
\text { MNA } \leq 17\end{array}$}} & $57.14 \%$ & \multirow[t]{13}{*}{$1, n=6$} & \multirow{3}{*}{\multicolumn{2}{|c|}{$\begin{array}{c}\text { MNA (17-23.5) } \\
\text { MNA } \leq 17\end{array}$}} & $83.33 \%$ \\
\hline & & & $28.57 \%$ & & & & $16.66 \%$ \\
\hline & & & $14.28 \%$ & & & & \\
\hline & \multicolumn{2}{|l|}{$75-84$ years } & $92.85 \%$ & & \multicolumn{2}{|l|}{$65-74$ years } & $100 \%$ \\
\hline & \multirow{3}{*}{\multicolumn{2}{|c|}{$\begin{array}{c}\text { Frail } \\
\text { Prefrail } \\
\text { Robust }\end{array}$}} & $50 \%$ & & \multirow{3}{*}{\multicolumn{2}{|c|}{$\begin{array}{c}\text { Robust } \\
\text { Frail }\end{array}$}} & $16.66 \%$ \\
\hline & & & $28.57 \%$ & & & & $83.33 \%$ \\
\hline & & & $21.14 \%$ & & & & \\
\hline & \multirow[t]{4}{*}{ No comorbidities } & 1 & $14.28 \%$ & & No comorbidities & 1 & $16.66 \%$ \\
\hline & & 3 & $21.42 \%$ & & & 4 & $33.33 \%$ \\
\hline & & 4 & $28.57 \%$ & & & 5 & $33.33 \%$ \\
\hline & & 5 & $28.57 \%$ & & & 6 & $16.66 \%$ \\
\hline & \multirow[t]{2}{*}{ No drugs } & 4 & $57.14 \%$ & & \multirow[t]{2}{*}{ No drugs } & 4 & $16.66 \%$ \\
\hline & & 5 & $14.28 \%$ & & & 5 & $50.0 \%$ \\
\hline \multirow[t]{11}{*}{$2, n=11$} & \multirow{3}{*}{\multicolumn{2}{|c|}{$\begin{array}{c}\text { MNA } \geq 24 \\
\text { MNA }(17-23,5) \\
\text { MNA } \leq 17\end{array}$}} & $27.27 \%$ & \multirow[t]{11}{*}{$2, n=7$} & \multirow{3}{*}{\multicolumn{2}{|c|}{$\begin{array}{c}\text { MNA }(17-23.5) \\
\text { MNA } \leq 17\end{array}$}} & $71.42 \%$ \\
\hline & & & $36.36 \%$ & & & & $28.57 \%$ \\
\hline & & & $36.36 \%$ & & & & \\
\hline & \multicolumn{2}{|l|}{$65-74$ years } & $100 \%$ & & \multicolumn{2}{|l|}{$75-84$ years } & $85.71 \%$ \\
\hline & \multicolumn{2}{|l|}{ Frail } & $81.81 \%$ & & \multicolumn{2}{|l|}{ Frail } & $100 \%$ \\
\hline & \multirow[t]{4}{*}{ No comorbidities } & 3 & $18.18 \%$ & & \multirow[t]{4}{*}{ No comorbidities } & 3 & $28.57 \%$ \\
\hline & & 4 & $18.18 \%$ & & & 5 & $71.43 \%$ \\
\hline & & 5 & $45.45 \%$ & & & & \\
\hline & & 6 & $18.18 \%$ & & & & \\
\hline & No drugs & 3 & $27.27 \%$ & & No drugs & 4 & $14.28 \%$ \\
\hline & & 5 & $27.27 \%$ & & & 5 & $71.42 \%$ \\
\hline $3, n=6$ & $M N A \geq 24$ & & $33.33 \%$ & $3, n=6$ & $M N A \geq 24$ & & $100 \%$ \\
\hline & MNA $(17-23$ & & $33.33 \%$ & & & & \\
\hline & $\mathrm{MNA} \leq 17$ & & $33.33 \%$ & & & & \\
\hline & $85-93$ years & & $100 \%$ & & $65-74$ year & & $33.33 \%$ \\
\hline & & & & & $75-84$ year & & $33.33 \%$ \\
\hline & & & & & 85-93 year & & $33.33 \%$ \\
\hline & Prefrail & & $16.66 \%$ & & Robust & & $66.66 \%$ \\
\hline & Frail & & $83,33 \%$ & & Prefrail & & $33.33 \%$ \\
\hline & No comorbidities & 4 & $16.16 \%$ & & No comorbidities & 1 & $50 \%$ \\
\hline & & 5 & $16.16 \%$ & & & 4 & $16.66 \%$ \\
\hline & & 6 & $33.33 \%$ & & & 6 & $33.33 \%$ \\
\hline & No drugs & 4 & $50.0 \%$ & & No drugs & 3 & 16.66 \\
\hline & & 5 & $33.33 \%$ & & & 4 & $16.66 \%$ \\
\hline & & & & & & 5 & $16.66 \%$ \\
\hline
\end{tabular}

Index Charlson - Gröningen Frailty Index $\left(\mathrm{r}=0.56^{\star}\right)$, Mini Nutritional Assesment - Gröningen Frailty Index ( $\mathrm{r}=$ $\left.-0.73^{\star}\right)$, Mini Nutritional Assesment - Geriatric Depression Scale $\left(\mathrm{r}=-0.78^{\star}\right)(\mathrm{p} \leq 0.05)$, the regression equations are: $\mathrm{y}=$ $1.9537+0.92131 * x, y=3.3253+0.56876{ }^{*} \mathrm{x}, \mathrm{y}=29.126-$ $1.017^{\star} \mathrm{x}, \mathrm{y}=27.345-0.7963{ }^{*} \mathrm{x}$ (Fig. 1-4).
As a result of these analyses, high positive and negative dependencies of the Gröningen Frailty index and Mini Nutritional Assesment, as well as the mathematical equations of dependencies were established, which is of predictive importance in medical practice.

Cluster analysis is a useful method for identifying pro- 
files associated with multifactorial aspects. The authors Fried L. et al. [2] and Rockwood K. et al. [28], who are the pillars of the concept of frailty, highlighted through this method the main aspects of the frailty phenotype model and the frailty index model.

In the present study, the most relevant indicators were used, which separated the clusters, such as: age category, frailty subtype, MNA nutritional score, number of chronic polypathologies and daily polymedications administered, which can be easily applied in trials clinics by nutritionists and clinicians [29]. At the same time, the aim was to elucidate the frequency of relevant clinical manifestations that would serve as markers of the evolution of frailty depending on nutritional status and sex.

The $k$-means cluster analysis divided the elderly into 2 sublots according to gender (female / male) with 21 different parameters, which included nutritional data, frailty, the presence of comorbidities and the number of drugs administered per day (tab. 1).

The cluster analysis by the centroid method of $k$-means established that the groups of elderly (female), separated into 3 clusters, differed according to the level and variability of the researched parameters. The elderly in cluster I were of the age category 75-84 years, who presented 3 subtypes of frailty with moderate prevalence of comorbidities, the daily administration of 4 drugs and the nutritional status not being affected. Cluster II was composed entirely of young elderly persons of the 65-74 age group, but more vulnerable in terms of frailty and nutritional status (risk of malnutrition - malnourished), associated with the highest number of chronic polypathologies (No 5), but with reduced drug use. Cluster 3 consisted mainly of old elderly people (85-93 years), with an equal frequency of normal nutritional status - risk of malnutrition - malnutrition, the most vulnerable in terms of vulnerability, with the highest number of chronic diseases (No 6) and the administration of the average number of daily drugs.

Regarding the age groups (male), they were distributed practically equally in number of participants, but with a frequency of different indices in clusters. Cluster I was composed of elderly people aged 65-74 years with the highest risk of malnutrition $-83.33 \%$, the highest share of frail, with the largest variety of comorbidities. Cluster II was noted for the highest frequency of frail people in the 75-84 age category with increased use of daily medication, and cluster III was noted for having the best indicator of nutritional status, being robust according to the frailty scale and using as a frequency the lowest number of prescribed medications.

Due to the comparative assessment between both groups of elderly (women / men), it can be mentioned that the normal nutritional status was found with a higher share in frail elderly in the category 75-84 years being associated with a high spectrum of comorbidities and lower comparative polymedicine with the same parameters in older men. The nutritional risk was found more frequently in frail elderly men in the young category of elderly (65-74 years) being associated with a wide range of comorbidities, and malnutri- tion was practically manifested equally in both groups from the study.

\section{Conclusions}

1. Frailty through its multidimensional aspects, has an increased prevalence among the elderly with an unfavorable prognosis.

2. Following a multilateral research, it was highlighted that insufficient nutrition and comorbidities can lead to the weakening of the institutionalized elderly through bio-psycho-social aspects.

3. According to the cluster analysis ( $k$-means method), the most relevant indicators that separated the clusters were: age category, sex, clinical scale of frailty, comorbidities and drugs.

4. The results obtained characterize the profile of institutionalized elderly and can be used as a basis for the development of effective strategies aimed at reducing physical, cognitive and social frailty.

5. The comparative evaluation between both groups of elderly people by gender, showed a normal nutritional status with a higher share in women in the group of 75-84 years, compared to older men, and malnutrition was practically manifested equally in both groups in the study (men/women).

\section{References}

1. Morley JE, Vellas B, van Kan GA, et al. Frailty consensus: a call to action. J Am Med Dir Assoc. 2013;14(6):392-397. doi: 10.1016/j. jamda.2013.03.022.

2. Fried LP, Ferrucci L, Darer J, et al. Untangling the concepts of disability, frailty, and comorbidity: implications for improved targeting and care. J Gerontol A Biol Sci Med Sci. 2004;59(3):255-263. doi.org/10.1093/ gerona/59.3.M255.

3. Kojima G, Kendrick D, Skelton DA, et al. Frailty predicts short-term incidence of future falls among British community-dwelling older people: a prospective cohort study nested within a randomised controlled trial. BMC Geriatr. 2015;15:155. doi: 10.1186/s12877-015-0152-7.

4. Fabrício-Wehbe SC, Rodrigues RAP, Haas VJ, et al. Association of frailty in hospitalized and institutionalized elderly in the communitydwelling. Rev Bras Enferm. 2016;69(4):691-696. doi.org/10.1590/00347167.2016690411i.

5. Amaral FL, Guerra RO, Nascimento AF, et al. Social support and the frailty syndrome among elderly residents in the community. Cien Saude Colet. 2013;18(6):1835-1846.

6. Hoogendijk EO, Suanet B, Dent E, et al. Adverse effects of frailty on social functioning in older adults: results from the Longitudinal Aging Study Amsterdam. Maturitas. 2016;83:45-50. doi: 10.1016/j.maturitas.2015.09.002.

7. Wong CH, Weiss D, Sourial N, et al. Frailty and its association with disability and comorbidity in a community-dwelling sample of seniors in Montreal: a cross-sectional study. Aging Clin Exp Res. 2010;22(1):54-62. doi: 10.1007/BF03324816.

8. Vermeulen J, Neyens JC, van Rossum E, et al. Predicting ADL disability in community-dwelling elderly people using physical frailty indicators: a systematic review. BMC Geriatr. 2011;11:33. doi: 10.1186/1471-231811-33.

9. Liu LK, Guo CY, Lee WJ, et al. Subtypes of physical frailty: latent class analysis and associations with clinical characteristics and outcomes. Sci Rep. 2017;7:46417. doi: 10.1038/srep46417.

10. Lorenzo-López L, Maseda A, de Labra C, et al. Nutritional determinants of frailty in older adults: a systematic review. BMC Geriatr. 2017;17(1):108-121. doi: 10.1186/s12877-017-0496-2. 
11. Bieniek J, Wilczyński K, Szewieczek J. Fried frailty phenotype assessment components as applied to geriatric inpatients. Clin Interv Aging. 2016;11:453-459. doi: 10.2147/CIA.S101369.

12. Checa-López M, Oviedo-Briones M, Pardo-Gómez A, et al.; FRAIL TOOLS consortium. FRAIL TOOLS study protocol: a comprehensive validation of frailty assessment tools to screen and diagnose frailty in different clinical and social settings and to provide instruments for integrated care in older adults. BMC Geriatr. 2019;19(1):86. doi: 10.1186/ s12877-019-1042-1.

13. Boulos C, Salameh P, Barberger-Gateau P. Malnutrition and frailty in community-dwelling older adults living in a rural setting. Clin Nutr. 2016;35(1):138-143. doi: 10.1016/j.clnu.2015.01.008.

14. Malmstrom TK, Miller DK, Simonsick EM, et al. SARC-F: a symptom score to predict persons with sarcopenia at risk for poor functional outcomes. J Cachexia Sarcopenia Muscle. 2016;7(1):28-36. doi: 10.1002/ jcsm. 12048 .

15. Statistics Canada; Turcotte M, Schellenberg G. A portrait of seniors in Canada: 2006. Ottawa: Minister of Industry; 2007 [cited 2021 Apr 12]. Available from: https://www150.statcan.gc.ca/n1/pub/89-519-x/89-519x2006001-eng.htm

16. Min L, Yoon W, Mariano J, et al. The vulnerable elders-13 survey predicts 5-year functional decline and mortality outcomes in older ambulatory care patients. J Am Geriatr Soc. 2009;57(11):2070-2076. doi:10.1111/j.1532-5415.2009.02497.x

17. Ćwirlej-Sozańska A., Sozański B, Wiśniowska-Szurlej A, et al. An assessment of factors related to disability in ADL and IADL in elderly inhabitants of rural areas of south-eastern Poland. Ann Agric Environ Med. 2018;25(3):504-511. doi: 10.26444/aaem/81311.

18. Rivolta MW, Aktaruzzaman M, Rizzo G, et al. Evaluation of the Tinetti score and fall risk assessment via accelerometry-based movement analysis. Artif Intell Med. 2019;95:38-47. doi: 10.1016/j.artmed.2018.08.005.

19. Larner AJ. Mini-Mental State Examination: diagnostic test accuracy study in primary care referrals. Neurodegener Dis Manag. 2018;8(5):301305. doi: $10.2217 / \mathrm{nmt}-2018-0018$.
20. World Health Organization. International Statistical Classification of Diseases and Related Health Problems. 10th Revision. ICD-10 Version 2019. Geneva: WHO; 2019 [cited 2021 Apr 12]. Available from: https:// icd.who.int/browse10/2019/en\#/

21. Kelaiditi E, Cesari M, Canevelli M, et al. Cognitive frailty: rational and definition from an (I.A.N.A./I.A.G.G.) international consensus group. J Nutr Health Aging. 2013;17(9):726-734. doi: 10.1007/s12603-013-0367-2.

22. Welsh TJ, Gordon AL, Gladman JR. Comprehensive geriatric assessment - a guide for the non-specialist. Int J Clin Pract. 2014;68(3):290293. doi: 10.1111/ijcp.12313.

23. Batko-Szwaczka A, Dudzińska-Griszek J, Hornik B, et al. Frailty phenotype: evidence of both physical and mental health components in community-dwelling early-old adults. Clin Interv Aging. 2020;15:141 150. doi.org/10.2147/CIA.S238521.

24. Bekić S, Babič F, Filipčić I, et al. Clustering of mental and physical comorbidity and the risk of frailty in patients aged 60 years or more in primary care. Med Sci Monit. 2019;25:6820-6835. doi: 10.12659/MSM.915063.

25. Montero-Odasso MM, Barnes B, Speechley M, et al. Disentangling cognitive frailty: results from the gait and brain study. J Gerontol A Biol Sci Med Sci. 2016;71(11):1476-1482. doi: 10.1093/gerona/glw044.

26. Saunders NL, Summers MJ. Longitudinal deficits to attention, executive, and working memory in subtypes of mild cognitive impairment. Neuropsychology. 2011;25(2):237-248. doi: 10.1037/a0021134.

27. Kwan RYC, Leung AYM, Yee A. et al. Cognitive frailty and its association with nutrition and depression in community-dwelling older people. J Nutr Health Aging. 2019;23(10):943-948. doi: 10.1007/s12603-019 1258-y.

28. Rockwood K, Song X, MacKnight C, et al. A global clinical measure of fitness and frailty in elderly people. CMAJ. 2005;173(5):489-495. doi: 10.1503/cmaj.050051.

29. Lee BS, Sen PK, Park NS, et al. A clustering method to identify who benefits most from the treatment group in clinical trials. Health Psychol Behav Med. 2014;2(1):723-734. doi:10.1080/21642850.2014.924857.

\author{
Authors' ORCID iDs and academic degrees \\ Felicia Lupascu-Volentir, MD, PhD, Superior Scientific Researcher - https://orcid.org/0000-0001-6380-4733 \\ Gabriela Soric, MD, PhD, Assistant Professor - https://orcid.org/0000-0001-5314-2270 \\ Ana Popescu, MD, Assistant Professor - https://orcid.org/0000-0002-2405-9125 \\ Anatolie Negara, MD, PhD, Associate Professor - https://orcid.org/0000-0002-8973-7310
}

\title{
Authors' contribution
}

FLV conceptualized the study, designed the research, collected and interpreted the data, drafted the first manuscript; GS conducted the laboratory work and revised the manuscript critically; AP collected data and revised the manuscript critically; AN conducted the management work and revised the manuscript critically. All the authors revised and approved the final version of the manuscript.

\section{Funding}

The study was supported by institutional research projects \#20.80009.8007.25 Frailty: diagnosis and prophylaxis in relation to the medicopsycho-social problems of the vulnerable elderly, Nicolae Testemitanu State University of Medicine and Pharmacy. The authors are independent and take responsibility for the integrity of the data and accuracy of the data analysis.

\section{Ethics approval and consent to participate}

The research was approved by the Research Ethics Committee of Nicolae Testemitanu State University of Medicine and Pharmacy (protocol No 51 of June 16,2020$)$.

Conflict of Interests

The authors have no conflict of interests to declare. 